УДК 811.1'42

ББК 81.055.1

DOI: https://doi.org/10.17308/lic.2021.4/3805

\title{
ПОЧЕМУ КРОССВОРД ЯВЛЯЕТСЯ ТЕКСТОМ?
}

\author{
Л. И. Гришаева, О. С. Макаренко \\ Воронежский государственный университет
}

\section{WHY IS A CROSSWORD PUZZLE A TEXT?}

\author{
L. I. Grishaeva, O. S. Makarenko \\ Voronezh State University
}

\begin{abstract}
Аннотация: в статье, посвященной текстограмматическому описанию типа текста «кроссворд», приводятся аргументы в пользу трактовки кроссворда как типа текста на основании того, что ему свойственны все интегральные текстовые признаки. Главные из этих признаков те, что кроссворд, как и любой текст, является результатом коммуникативной деятельности носителей культуры, способом фиксации этого результата, конвенционально принятого в определенной языковой культуре и конвенционально оформляемого в этой среде. Кроссворд, будучи текстом, представляет собой функииональную, содержательную, структурную, интенциональную целостность. Кроссворд, как каждый текст, - это способ решения носителями языка и культуры с помощью разнородных языковых средств некоторой коммуникативной и когнитивной задачи в известных коммуникативных условиях. С помощью процедур макроструктурного анализа, и прежде всего текстосемантического и текстосинтаксического, описьваются особенности проявления у него основных свойств, присущих тексту как феномену в различных лингвокультурных пространствах. Характеризуется также специфика реализации интегральных текстовых признаков в коммуникативных образованиях данного типа, обусловленная принадлежностью кроссвордов к классу людических текстов. Описываются средства и способы выражения текстовых категорий в текстах анализируемого типа. Наиболее внимательно изучаются способы активизации сведений в кроссворде, поскольку названное ментальное действие является текстообразующим стержнем, значимым в текстоорганизуюшем смысле как со структурной, так и с содержательной и функииональной точек зрения. Сущность типа текста «кроссворд» определяется через его свойства как семиотически осложненного, т. е. поликодового, текста с полной креолизаџией. Через сравнение способов функииональной, семантической и синтаксической организации текстов данного типа в двух языковых культурах - немецкой и русской - определяются тематические сферы, активируемые в кроссворде, что позволяет судить о степени значимости знания, разделяемого всеми носителями языка и культуры и получить доступ к иерархии связей между различными ментальными структурами в картине мира соответствующего коллективного субъекта как носителя культуры.

Ключевые слова: текст, тип текста, категории текста, средства выражения текстовых категорий, способы установления когерентности, интегральные и дифференщиальные признаки текста.
\end{abstract}

\begin{abstract}
The arguments are given in favour of the interpretation of the crossword as a type of text on the basis that it possesses all integral textual features. The main of these features are the following: the crossword puzzle, like any text, is the result of the communicative activity of members of a particular culture, a way of capturing the result which is conventionally accepted in a specific language and culture and conventionally formed in this environment. A crossword puzzle, being a text, demonstrates functional, meaningful, structural and intentional integrity. A crossword puzzle, like every text, is a way for people as speakers of language and members of culture to solve a certain communicative and cognitive problem within certain communicative settings using heterogeneous linguistic means. Using the procedures of macrostructural, primarily textual semantic and textual syntactic analysis, the authors
\end{abstract}

(С) Гришаева Л. И., Макаренко О. С., 2021

Контент доступен под лицензией Creative Commons Attribution 4.0 License.

The content is available under Creative Commons Attribution 4.0 License. 
describe the features of the manifestation of the main inherent textual properties of the crossword as a phenomenon in various linguistic and cultural spheres. The article also describes the specifics of the implementation of integral text features in crosswords as the ludic type of text. The means and methods of expressing textual categories in texts of the analyzed type are described. The methods of activating information in a crossword puzzle are carefully studied, since the mental action is a text-forming basis, significant for the organization of the text both from the structural and from the semantic and functional points of view. The essence of the crossword as a specific type of text is defined through its properties as a semiotically complicated, i.e., multimodal text in which creolization is accomplished. By comparing the ways of functional, semantic and syntactic organization of texts of this type in two languages and cultures - German and Russian - the thematic spheres activated in the crossword are determined, which allows the authors to evaluate the degree of significance of knowledge shared by all native speakers of the language and members of the culture and to gain access to the hierarchy of connections between various mental structures in the worldview of the corresponding collective subject as a representative of culture.

Key words: text, type of text, textual categories, means of expressing of textual categories, ways of establishing coherence, integral and differential features of the text.

\section{Введение}

Предлагаемое читателям исследование представляет собой развернутую аргументацию трактовки кроссворда в качестве текста определенного типа, обладающего интегральными и дифференциальными текстовыми признаками.

Необходимость подобной постановки вопроса обусловлена тем, что до сих пор отсутствует ясность относительно соотношения интегральных и дифференциальных текстовых признаков как применительно к конкретным текстам, так и к текстам того или иного типа, т. е. классам текстов. Доминирует имплицитное - и зачастую даже не осознаваемое исследователями - представление о правомерности и правомочности экстраполирования теоретически выверенного знания относительно принципов организации текста на микроуровне на организацию текста на макроуровне.

Другими словами, принципы содержательной, функциональной, структурной организации текстовой ткани части целого по умолчанию переносятся на более сложное во всех отношениях образование - цельный текст. Поэтому и выявляемые при исследовании аберрации разной этиологии объясняются либо идиостилистическими и/или когнитивно-стилистически обусловленными особенностями использования языка как средства познания и коммуникации адресантом, порождающим конкретный текст, либо спецификой условий, внешних и/или внутренних по отношению к порождаемому тексту, либо влиянием некоторого фактора когнитивной, социологической, психологической, исторической, интеракциональной, культурологической, антропологической, лингвистической и прочей природы, способствующей либо препятствующей реализации тех или иных свойств текста как феномена. Преувеличенное внимание уделяется при этом универсальным закономерностям организации текста, и наоборот, преуменьшается значимость изучения соотношения общего и частного, универсального и культурно специфического в организации текста как на микро-, так и на макроуровне (см. подробнее анализ соответствующего проблемного поля в $[1 ; 2])$.

\section{Постановка проблемы и актуальность исследования}

Сказанное выше относится к тексту буквально любого типа. Внимание же к кроссворду обусловлено тем, что он, в каком бы виде не встречался в языковой культуре, бесспорно, являет собой на сегодняшний день одно из наиболее популярных и активно востребованных в людической коммуникации сложно организованных полифункциональных образований.

В специальной литературе, однако, практически отсутствуют труды, авторы которых стремятся изучить кроссворд с лингвистических, текстограмматических, позиций [3]. Работы, объектом анализа в которых является кроссворд, решают прежде всего и преимущественно педагогические и дидактические задачи, раскрывая под разным углом зрения лингводидактическое и культурологическое функциональное богатство обсуждаемого коммуникативного явления.

Стоит обратить внимание и на то, что тип текста «кроссворд» не фиксируется как таковой в типологиях текста, выстраиваемых на самых разных основаниях и появившихся в разные периоды развития теории текста и/или типологии текста (см., например, [4-8]), несмотря на довольно длительную по современным меркам историю бытования кроссворда в языковых культурах ${ }^{1}$.

\footnotetext{
${ }^{1}$ До сих пор нет единства мнений относительно того, где впервые появилась головоломка «кроссворд»: в Англии, США или ЮАР. Многие считают, что, скорее всего, 21 декабря 1921 г. в рождественском издании газеты "New York World" напечатан первый кроссворд - «магический квадрат», состоявший из 31 вопроса, в котором не было черных, пустых, клеток. Автором этой головоломки был ливерпульский журналист Артур Уинн, придавший позднее своей головоломке ее современный вид. Есть и иная позиция, согласно которой житель ЮАР
} 
В обозначенном контексте особого упоминания заслуживает публикация О. С. Макаренко, которая сфокусировала свой исследовательский интерес на выявлении средств и способов активизации сведений о мире в кроссвордах разного вида, подчиняя их описанию названного коммуникативного образования с текстограмматических позиций [9].

Одной из важных причин, вызывающих особый лингвистический интерес к кроссворду как типу текста, являются актуальные для современного состояния общества тенденции, способствующие появлению новых дискурсивных практик, реализуемых носителями разных языков и культур в разных условиях, например, разнообразные виды компьютерноопосредованной коммуникации. Освоение коммуникантами новых дискурсивных практик, вне всякого сомнения, способствует появлению новых коммуникативных и когнитивных задач, а также новых способов их решения и как следствие - новых типов текста, регистрирующих специфическое функционирование разнородных языковых средств, т. е., по сути, представляющих новые способы реализации коммуникативных стратегий, которыми располагают коммуниканты как носители языковой культуры². Упоминания заслуживают в первую очередь тенденции к информатизации, медиализации, виртуализации, коммерциализации, индивидуализации, гедонизму, манипулятивности и др., которые наиболее отчетливо проявляют себя на современном этапе развития информационного общества $[12 ; 13]$.

На примере изучения принципов организации кроссворда можно проследить реализацию актуальных для организации текста тенденций, таких как креолизация, диалогичность, изменение соотношения оральной и скриптуральной традиций в использовании языковых средств, увеличение доли интертекстуальности в текстовой ткани, интенсивное использование средств образности и др. [1; $2 ; 14 ; 15 ; 16 ; 17]$.

по имени Виктор Орвилл, отбывая тюремное наказание за то, что сбил автомобилем свою жену, от скуки придумал новую игру, заключавшуюся в записывании слов по буквам на плитках пола камеры. Он поделился своей игрой с одной из кейптаунских газет, напечатавшей его кроссворд [10]. Изобретателем головоломки считают также англичанина Майкла Девиса, так как, по некоторым данным, его кроссворды печатали в газете «Таймс» еще в XIX в. Первый русский кроссворд придумал Владимир Набоков в Германии 22 февраля 1925 г. Испытывая денежные затруднения, он составил головоломку, назвав ее крестословицей [11].

2 Достаточно вспомнить в этой связи реализацию в коммуникативном пространстве таких стратегий, как конструирование фейков, конструирование симулякров, манипуляции разного рода, пранкинг, хейтинг, троллинг, флейминг и т. д., которые стали настолько востребованными, что многие коммуниканты оказываются не в состоянии отграничить их, например, от информирования, повествования и пр.
Подобный ракурс анализа важен не только в частнотеоретическом отношении, т. е. для описания кроссворда как типа текста, но и в общетеоретическом смысле, т. е. для осмысления изменений принципов содержательной, формальной и функциональной организации текста как феномена на микро- и макроуровне. Так, изучение способов реализации диалогичности как текстовой категории, столь свойственной игровой коммуникации, позволяет проследить тенденцию к изменению соотношения монологичности - диалогичности в разных типах текстов, столь характерной в актуальных условиях для содержательной и структурной организации даже традиционно монологических текстов, например, в инструкциях, лекциях, монографиях, статьях, и форматах общения, и тем самым объяснить многочисленные метаморфозы в текстах разного типа, столь очевидные для исследователя в разных коммуникативных сферах (например, в научной коммуникации, в медиапространстве, в неофициальном общении, в виртуальной сфере и т. д.).

В обозначенном контексте значимость изучения кроссворда становится более выпуклой также по причине того, что кроссворд по определению не может не отразить культурно-специфические представления об окружающем мире конкретной группы людей - в нем часто и прежде всего активизируются прецедентные феномены, т. е. знания, разделяемые всеми носителями языка и культуры. Другими словами, создатель кроссворда не может не ориентироваться на коллективного субъекта и в силу этого - на структуры декларативных и процедуральных сведений, относящихся к ядерной части ментальной структуры личностной и коллективной идентичности единичного субъекта. Поэтому кроссворд как тип текста становится надежным источником сведений о структуре картины мира и способах категоризации мира.

Изложенные соображения обосновывают актуальность предпринятого исследования.

\section{Цель и задачи исследования}

Цель исследования - через изучение особенностей организации на микро- и макроуровне кроссвордов как результатов деятельности Homo ludens выявить особенности функциональной, содержательной и структурной организации типа текста «кроссворд». Это позволяет проследить соотношение интегральных и дифференциальных текстовых признаков в кроссворде, а также получить доступ к данным относительно ментальной структуры картины мира и ментальной структуры коллективной и личностной идентичности носителей языка и культуры. 


\section{Материал и методика исследования}

Материалом для исследования стали 30 кроссвордов нескольких разновидностей (сканворд, классический кроссворд, фигурный кроссворд), в которых тем или иным способом зашифрованы более 1000 понятий, проанализированных с разных точек зрения [18]. Всего описано 232 пары «вопрос - ответ», извлеченные из русского эмпирического материала, и 286 из немецкого.

Чтобы добиться поставленной цели, осуществлялось многоаспектное и комплексное изучение кроссворда. Поэтому очевидно, что методика описания отобранного материала предполагает различные виды анализа, подчиненные текстограмматическому описанию изучаемого типа текста: дефиниционный, когнитивный, лексико-семантический, морфологический, синтаксический, текстограмматический, а также количественный анализ описываемых единиц, классификацию изучаемых единиц в опоре на разнородные критерии с учетом тематической соотнесенности и структурных особенностей языковых средств, в том числе и сравнительный анализ эмпирии на микро- и макротекстовом уровнях.

Пристальное внимание уделяется макросемантическим и макросинтаксическим особенностям организации текста анализируемого типа. Это позволяет проследить принципы структурирования информационного потока, т. е. последовательность и степень детализации комплексов сведений о мире при их активизации в процессе порождения текста и при фиксации этой последовательности в текстовом пространстве [1; 19].

Единицей анализа является вопросно-ответная секвенция, интерпретируемая в текстограмматических терминах как сверхфразовое единство (СФЕ) и как макрокомпонент текстовой структуры. Совокупность макрокомпонентов и особенности их сочленения в текстовой целостности и образуют коммуникативное, интенциональное, структурное, функциональное единство «текст». Правомерность подобной трактовки основывается на том, что следующие свойства СФЕ оказываются присущими и минимальному структурному компоненту кроссворда вопросно-ответной секвенции:

- активизация сведений о мире из одной понятийной сферы, т. е. тематическое единство СФЕ;

- реализация одного вида тема-рематической прогрессии в пределах СФЕ, т. е. синтаксическое и коммуникативное единство СФЕ;

- целостность СФЕ в структурном, содержательном, функциональном отношении;

- членимость СФЕ, т. е. наличие в нем нескольких текстем как компонентов СФЕ, связанных тема-рематическими отношениями;
- грамматичность СФЕ, поскольку каждая текстема как элемент СФЕ порождается в содержательном, структурном и функциональном отношении по грамматическим законам соответствующего языка.

Анализ кроссворда как типа текста осуществляется в несколько этапов:

1) описание кроссворда как типа текста:

- выявление текстовых характеристик в кроссворде;

- изучение соотношения интегральных и дифференциальных признаков типа текста «кроссворд»;

- определение функционального потенциала типа текста «кроссворд»;

2) выявление и описание средств и способов выражения текстовых категорий;

3) определение средств и способов активизации сведений о мире;

4) исчисление средств и способов апелляции к прецедентным феноменам как доминирующему при макроструктурной организации кроссворда;

5) сопоставление способов структурной, содержательной, функциональной организации кроссворда на микро- и макротекстовом уровне в русской и немецкой языковой культурах;

6) обобщение наблюдений и формулирование значимых корреляций.

\section{Интегральные текстовые признаки в кроссворде как типе текста}

Характеристики текста, ставшие классическими, достаточно давно выделены и детально описаны с разных сторон на материале разных языков и разных классов и типов текста (см. труды прежде всего немецких и отечественных исследователей, имеющих общепризнанно особые заслуги в теории текста [5; $15 ; 16 ; 19-30])$. Консенсус исследователей в данной области исследований зафиксирован в лингвистических словарях разного года изданий и сводится к тому, что основой текстуальности, позволяющей отграничивать текст от не-текста, является когерентность. В этой связи акцентируется и этимология слова textus - ткань, сплетение, соединение. Так, в Лингвистическом энциклопедическом словаре текст определяется как «объединенная смысловой связью последовательность знаковых единиц, основными свойствами которой являются связность и цельность» [31, с. 507].

Под разными углами зрения анализируются текстовые категории и разнообразные и разноуровневые средства их выражения: адресованность, темпоральность, модальность, локативность, интертекстуальность, авторитетность, а также грамматичность, тема-рематическая прогрессия, (поли)тематичность, диалогичность, интенциональность, соци- 
альная приемлемость и пр. В качестве соответствующих вербальных средств выражения текстовых категорий рассматриваются лексико-семантические, словообразовательные, морфологические, синтаксические, формально-структурные, текстограмматические, которые правомерно в целях анализа дифференцировать по более тонким основаниям (см. детальное описание соответствующих групп в [1, с. 21-74]).

Для креолизованных текстов во внимание принимаются также разнообразные невербальные средства: цвет, звук, форма и пр., т. е. средства разных невербальных кодов, поскольку в качестве текстов описываются различные коммуникативные образования: видео- и аудиопродукция, теле- и интернет-продукция и т. д. $[14 ; 32 ; 33]$.

Исследователи текста разных направлений и школ, отмечая универсальность некоторых свойств текста как феномена, подчеркивают ряд обстоятельств особо. При этом главным образом внимание обращается на специфику реализации свойств, имманентных тексту, в отдельных классах и типах текстах, а также в той или иной языковой культуре. Кроме того, в фокусе дискуссий относительно способов функциональной, содержательной, формальной организации текста на микро- и/или макроуровне до сих пор оказываются вопросы о сущности типа текста и по-прежнему о природе текста. Вопросы, которые нет-нет да всплывают при обсуждении тех или иных проблем теории текста: текст - это знак? (или ведь текст - это знак особого рода), текст строится по модели? (или текст реализует модель) и т. п. Те же вопросы высвечиваются в некоторых формулировках, которые могут даже просто воспроизводиться в силу привычки. Теоретическую значимость корректных формулировок необходимо, однако, подчеркивать ради прояснения позиции, хотя бы потому, что подавляющее большинство исследователей сегодня и в своих теоретических рассуждениях, и в своей исследовательской практике признают за текстом его коммуникативную природу и статический характер как результата дискурсивной деятельности коммуникантов (см. процитированные выше труды).

В обозначенном контексте ничто не препятствует интерпретации кроссворда как текста, ведь кроссворд уже своей формой «воспроизводит» соответствующие представления - разное сплетение вертикально и горизонтально ориентированных нитей одной природы (шелк, хлопок, лен, крапива и т. д.) создает различные виды ткани: разного рисунка, разной плотности, в итоге получаются продукты с неидентичными свойствами, имеющие различное предназначение и пр.

Поэтому при характеристике кроссворда в качестве текста лингвистической проблемой является не возможность выявления текстовых категорий в том или ином коммуникативном продукте, порожденном с помощью языковых средств, а определение средств выражения соответствующих категорий и исчисление их функционального потенциала.

Данное обстоятельство необходимо четко осознать, поскольку в современных условиях появляются все новые способы использования языка в новых форматах общения между носителями языка и культуры. Следовательно, если иметь в виду общетеоретический ракурс рассуждений, требуются, с одной стороны, проверка объяснительной силы существующих теорий и процедур анализа и, с другой стороны, разработка новых приемов и обоснование новых концепций, обеспечивающих приращение нового лингвистического знания.

Для кроссворда анализ на предмет наличия в нем текстовых категорий завершается естественным позитивным ответом, поскольку:

- кроссворд интенционален - его автор конструирует эту головоломку для развлечения адресата, предлагая последнему задания разной степени сложности, бросая ему своего рода вызов на интеллектуальную дуэль;

- кроссворд адресуется определенной категории адресата, причем адресант, порождающий кроссворд, учитывает возрастные, гендерные, профессиональные, социокультурные, психологические и иные особенности людей, которые будут заниматься соответствующей головоломкой. При этом любопытно подчеркнуть, что адресант, порождающий текст, как правило, является носителем личностной идентичности и выступает в дистантной коммуникации как единичный субъект, а адресат в стандартном случае воспринимается адресантом носителем коллективной идентичности, хотя в коммуникации тот является, бесспорно, единичным субъектом;

- кроссворд политематичен - в нем вербальным и невербальным способами активизируются знания о мире из самых разных областей. При этом один кроссворд может быть в этом отношении менее разнообразным, а другой - наоборот;

- кроссворд грамматичен - для успеха решения этой задачи значимыми и обязательными оказываются не только содержание, активируемое вербальными и/или невербальными средствами, но и корректная орфография (!), которая, кстати, во многих форматах коммуникации факультативна. (Ср. только манеру составления текстов в компьютерно-опосредованной коммуникации, например, при порождении СМС-сообщений, в чатах, электронных письмах и пр. Да, впрочем, и наличие опечаток в письменной научной коммуникации, которые зачастую не сказываются фатально на продуктивности коммуникации.) При решении кроссворда несоблюдение орфографических правил, т. е. аграмматичность, становится серьезным 
препятствием для достижения коммуникативной цели;

- кроссворд интертекстуален в силу своей природы; он основывается на знаниях, разделяемых всеми носителями языка и культуры, т. е. сведениях, относящихся к ядерной части ментальной структуры коллективной идентичности носителей языка и культуры. Если бы это было иначе, кроссворд вряд ли бы смог завоевать популярность и получить развитие. Одним из наиболее эффективных способов активизации сведений о мире в кроссворде, как показывает исследование [18], является апелляция к прецедентным феноменам разного рода, т. е. интертекстуальность;

- кроссворд обладает диалогичностью, причем взаимодействие между адресантом и адресатом дистанционно в локальном и темпоральном отношении: кроссворд, созданный в одну эпоху, можно разгадывать в другую. Степень успешности решения зависит от уровня эрудиции конкретного субъекта, уровня владения языком, на котором составлен кроссворд, степенью заинтересованности адресата и пр., т. е. в конечном итоге от социопсихологических особенностей коммуниканта. Для коммуникации посредством кроссворда характерно то, что адресат кроссворда непосредственно и активно участвует в своего роде беседе, являющейся квази-открытой, но уверенно направляемой автором такой викторины. Выражаясь иначе, форма (пустые ячейки) парадоксальным образом способствует развитию содержательного диалога между обоими коммуникантами.

Аналогичный комментарий можно сделать и по отношению к другим текстовым категориям; этот комментарий, однако, целесообразно сознательно вынести за скобки из-за понятных формальных соображений. Особого обсуждения, между тем, заслуживает тема-рематическая прогрессия как важный параметр любого текста.

В подавляющем большинстве случаев, однако отнюдь не абсолютно всегда, тема-рематическую прогрессию в вопросно-ответной секвенции можно схематично представить следующим образом: $T 1$ (Th $\left.-R h_{l}\right)-T 2\left(R h_{2}\right)$, или же $T 1\left(R h_{l}\right)-T 2\left(R h_{l}\right)$ либо $T 1$ $\left(R h_{1}\right)-T 2(R h 2)$, где $T$ - тема, а $T h / R h$ - тема и рема соответственно. Например, kreisen, wenden (drehen) ${ }^{3}$, franz. weiblicher Artikel (la), Roman von Herman Merville (Mobydick), гроза речных браконьеров (Роскомнадзор), пирожное из взбитых яичных белков и сахара (безе), оптический прибор, применяемый для получения увеличенного изображения на экране (проектор).

${ }^{3}$ Информационную структуру вопросно-ответной секвенции можно интерпретировать - при желании - и несколько иначе: kreisen, wenden $(=T 1(T h))$ (drehen) $\left(=T 2\left(R h_{l}\right)\right)$ или же $T 1\left(=R h_{1}\right)-T 2\left(R h_{2}\right)$.
Следует подчеркнуть, что трактовка тема-рематической прогрессии в вопросно-ответной секции, по всей видимости, зависит не столько от тематической сферы, из которой активизируются соответствующие сведения о мире, сколько от разновидности кроссворда, синтаксической формы обеих текстем, образующих вопросно-ответную секвенцию, а также от позиции исследователя относительно сути тема-рематического членения и/или тема-рематической прогрессии в простом и/или сложном предложении или в группе слов, а также в СФЕ в целом. Тем не менее данная проблема еще ждет своего решения, поскольку объем эмпирического материала в обсуждаемом исследовании не позволяет еще высказываться более определенно.

Еще одной важнейшей характеристикой кроссворда является специфика его рецепции. Процесс рецепции кроссворда и процесс рецепции других типов текста существенно различается: если рецепция «традиционного» текста, как правило, линейна, то при разгадывании кроссворда исходный текст, порожденный адресантом, последовательно и линейно воссоздается на микроуровне (в пределах одной вопросно-ответной секвенции). Но воссоздание порядка следования вопросно-ответных секвенций в макроструктуре в большинстве случаев оказывается весьма вариативным, что тем не менее не влияет на конечный результат. И поэтому за воспроизведением первой секвенции может наступить очередь двадцатой и т. д. Последовательность шагов адресата по воссозданию текста в целом, таким образом, не может не отличаться от действий адресанта, поскольку условия порождения текста, естественно, совершенно иные, чем ситуация, в которой воспринимает текст адресат.

Однако имеются такие разновидности кроссворда, в которых последовательность рецепции играет более существенную роль, чем для, например, классического кроссворда - речь идет прежде всего о чайнворде. Другими словами, макроструктурная организация типа текста «кроссворд» вариативна.

С текстоорганизующих позиций весьма важно обратить внимание на то, какие типы связи присутствуют в тексте. Здесь явно прослеживаются внутритекстовые, межтекстовые и интертекстуальные связи, выявляемые по разнообразным основаниям, традиционным для анализа принципов организации текста как феномена (см. аргументацию для разграничения названных типов связей в тексте в [1]). Внутритекстовые связи, значимые для конструирования каждого из образующих текст СФЕ и макротекста в целом, можно проследить прежде всего по лексико-семантическим, словообразовательным, морфологическим, синтаксическим, формально-структурным, а также стилистическим, логическим и когнитивным основа- 
ниям. Межтекстовые и интертекстуальные связи играют большую роль на макротекстовом уровне. Например, amerikanischer Schriftsteller Irving (John), Roman von Herman Merville (Mobydick), злобное сказочное сущчество (орк). Выражаясь иначе, наличие внутритекстовых, межтекстовых, интертекстуальных связей в типе текста «кроссворд»-это интегральный признак текста анализируемого типа, однако конфигурация связей в текстовом пространстве - дифференциальный, поскольку степень востребованности соответствующих сведений в текстовом пространстве кроссворда зависит не только от культуры и/или личностной идентичности автора кроссворда, но и от типа последнего.

\section{Дифференциальные текстовые признаки в кроссворде как типе текста}

Наряду с интегральными текстовыми признаками целесообразно различать две группы дифференциальных признаков: 1) признаки, обусловливающие организацию каждого текста, порождаемого в конкретной языковой культуре, в силу культурной специфики; 2) признаки, свойственные определенному классу текста независимо от характера культурной среды.

В первом случае речь идет, по сути, об особенностях реализации универсальных для текста признаков, например, организация лекции, интеллектуального романа, личного письма интеллектуала, кулинарного рецепта и пр. в немецкой/русской/английской/... языковой культуре.

Во втором случае имеются в виду как интегральные, так и дифференциальные признаки, имманентные только одному классу текстов, к которому можно отнести несколько типов текста, обладающих некоторым достаточно устойчивым набором и интегральных, и дифференциальных признаков. Например, содержательная/функциональная/формальная организация на микро- и/или макроуровне в русской языковой культуре информативных/коммиссивных/ экспрессивных/дескриптивных/... текстов.

Признаки второй группы есть резон распределить также по двум подгруппам: 2.1) дифференциальные признаки, свойственные классу текстов, т. е. всем людическим текстам; 2.2) признаки, присущие типу текста как компоненту соответствующего класса, когда исследователю приходится принимать во внимание разную степень выраженности интегральных для класса текстов дифференциальных признаков и разные способы реализации соответствующих характеристик. Другими словами, необходимо при анализе учитывать уровень иерархии (степень универсальности или культурной специфичности) того или иного текстового признака.

Кроссворд, будучи текстом, обладает, как уже сказано, такими интегральными текстовыми призна- ками, как интенциональность, цельность, связность, (поли)тематичность, диалогичность, интертекстуальность и др. Однако для дифференциальной характеристики необходимо подчеркнуть, что когерентность типа текста «кроссворд» реализуется по вертикали и горизонтали, т. е. для когерентности текста анализируемого типа важен такой дифференциальный признак, как иерархичность связности на микро- и макроуровне. При этом в текстоорганизующем отношении оказывается более значимой не локальная, а глобальная связность.

Когерентность реализуется не только вербальными, но и невербальными средствами: цифры служат точками ориентирования между заданиями и потенциальными узлами связи в текстовом пространстве, а коннекторами выступают общие буквы. Другими словами, цифры - формальные средства когезии как внутри вопросно-ответной секвенции, т. е. на микроуровне текста, так и на текстовом макроуровне между отдельными секвенциями. Выражаясь иначе, формально-структурные механизмы, например орфографические, играют бо́льшую роль, чем содержательные.

Наличие языковых и невербальных средств и способов реализации когерентности в кроссворде ставит вопрос о распределении функциональной нагрузки между отдельными средствами когезии в текстовом пространстве. На сегодняшнем этапе результаты анализа позволяют прийти к суждению об относительно равноправном распределении функциональной нагрузки между вербальными и невербальными средствами по крайней мере в классическом кроссворде. Более определенно об этом можно судить после детального специального изучения обсуждаемой проблематики на более обширном эмпирическом материале.

В качестве существенного дифференциального признака следует назвать также то, что каждая вопросно-ответная секвенция, будучи конститутивным компонентом членения макроструктуры текста, обладает собственной специфической организацией. При этом текстема, выполняющая функцию вопроса, выражается повествовательными структурами, которые чаще всего являются монорематическими. Эта текстема имеет в классическом кроссворде дистантную анафорическую связь со второй текстемой, являющейся ответом на вопросительную текстему, и реализуемой невербально и формально-грамматически (некоторое количество пустых ячеек, цифры), а также катафорическую с третьей текстемой (ответом). Катафорическая связь может варьироваться: она бывает либо квази-контактной (если кроссворд печатается с ответами), либо дистантной (если ответы не публикуются при кроссворде). 
Макроструктурная организация типа текста «кроссворд» варьирует в зависимости от разновидности кроссворда.

Таким образом, с текстограмматической точки зрения кроссворд представляет собой комплекс СФЕ (вопросно-ответных секвенций), организованных в функциональном, содержательном и структурном отношении. Текстемы как неотъемлемые компоненты СФЕ представляют собой в стандартном случае эллиптическую монорематическую структуру с выраженной коммуникативной функцией, построенной по грамматическим законам соответствующего языка.

Кроссворд остается цельным в структурном, функциональном, прагматическом отношении независимо от своей разновидности и сохраняет на протяжении всей коммуникации константное отношение между адресантом и адресатом.

Реализация признаков текстуальности, присущих тексту «кроссворд» как феномену, средствами вербального и невербальных кодов свидетельствует, следовательно, об обязательном присутствии в текстовой ткани интегральных и дифференциальных текстовых признаков, ингерентных как тексту вообще, так и определенному типу текста. Внимания заслуживают в первую очередь такие, как социальная приемлемость, наличие тема-рематической прогрессии, грамматичность, интертекстуальность, (поли) тематичность, членимость на микро- и макроуровнях, (относительное) функциональное равноправие вербальных и невербальных средств выражения текстовых категорий, связность между компонентами макроструктуры, вариативность в семантическом, структурном, функциональном отношении.

Макроструктуру текста пронизывают линейные и иерархические внутритекстовые, межтекстовые и интертекстуальные связи, выявляемые по разным основаниям, в том числе по невербальным, формальным, логическим и когнитивным.

Для описания кроссворда значимой остается диалектика универсального и специфического для текста как феномена и типа текста «кроссворд»в разных языковых культурах, поскольку конструирование кроссворда тесно - и, пожалуй, причинно связано с культурной идентичностью носителей языка и культуры.

\section{Кроссворд как креолизованный текст с полной креолизацией}

Присутствие в кроссворде как тексте вербальных и невербальных средств и способов реализации когерентности, а также способов выражения текстовых категорий дает основание характеризовать данный тип текста как креолизованный, т. е. семиотически гетерогенный, и обладающий полной креолизацией, согласно классификации креолизованных текстов
Е. Е. Анисимовой [33]. (Сp. нетождественную, но вполне сопоставимую характеристику поликодовых текстов в других теориях полимодальных коммуникативных образований, например, в [32].) Полной степень креолизации следует признать потому, что без невербальных средств - в частности, например, без пустых ячеек в классическом кроссворде или без цифр - содержательная и формальная макроструктура текста «кроссворд» разрушается, и сам текст не способен выполнять свое предназначение в культуре.

\section{Кроссворд как людический текст}

Обосновать кроссворд как людический текст значит показать, что кроссворд включен в людическую деятельность человека. Игра как вид деятельности известна уже с древнейших времен, является одной из сущностных характеристик человека и выполняет в социуме самые разные функции. Й. Хёйзинга утверждает, что в основе любой человеческой деятельности, а также самой культуры лежит игра, которая зачастую носит агональный характер, поэтому человека он назвал homo ludens - человек играющий [34]. Другими словами, людическая коммуникация располагает богатым набором разнообразных средств и выполняет в коммуникации не только рекреационные функции ${ }^{4}$.

Причисляя кроссворд к людическим текстам, целесообразно опираться на мнение Х. Изенберга, разработавшего матрицу для описания текстов разных классов и типов [4, S. 267-268]. В матрицу Х. Изенберг включил шесть классов текстов: гносогенные (gnosogene Texte), межличностные (kopersonale Texte), эрготропные (ergotrope Texte), эстетические (kalogene Texte), религотропные (religiotrope Texte), лудофильные (ludophile Texte). Чтобы описать выделенные классы текстов, исследователь опирается на следующие критерии, входящие в матрицу: общая характеристика (globales Bewertungskriterium), основная цель интеракции (fundamentales Interaktionsziel), частные коммуникативные задачи (partikulare Interaktionsziele). Согласно Х. Изенбергу, людофильные тексты - это разного рода загадки (Ratespiel,

${ }^{4}$ Интересно, что Р. 3. Назарова, М. В. Золотарев доказывают, что не только язык в целом, но и его обособленные элементы обладают людической функцией. Уделяя пристальное внимание прецедентным феноменам, они наряду с традиционными для игры слов явлениями замечают людический потенциал у других средств, как правило, не рассматриваемых под данным углом зрения. Так, по их наблюдениям, носители языка, чтобы оживить разговор, зачастую прибегают также к прецедентным феноменам. В результате коммуникант может преобразовать форму прецедентного феномена на свой лад, демонстрируя тем самым остроумие. Людические средства могут служить и утилитарным, а то и манипулятивным, целям, например, когда прецедентный феномен употребляется для того, чтобы подольститься к партнеру по коммуникации [35]. 
Konversationsspiel, Rätselraten, Orakelspiel, Sprechspiel u.a.). Основная цель таких текстов - развлечение здесь и сейчас (momentane Lusthaftigkeit), цель интеракции - совместное веселье (Erzielung eines gemeinschaftlichen Lustgewinns), а частные коммуникативные задачи - презентация информации, анализ информации, переструктурирование сведений, пополнение сведений [4].

Как показал анализ, всем перечисленным характеристикам людических (людофильных) текстов удовлетворяет, таким образом, и кроссворд.

\section{Функциональный потенциал кроссворда}

Основываясь на характеристике людофильных текстов, предложенной Х. Изенбергом (см. выше), можно сказать, что кроссворд полифункционален: он предоставляет коммуниканту разнородную информацию, способствует ее анализу, расширяет эрудицию коммуниканта, переструктурирует имеющиеся у коммуниканта сведения о мире в разных ментальных структурах, трансформирует его картину мира. Вместе с тем кроссворд, который, как правило, решают на досуге, выполняет прежде всего рекреационные функции - он служит развлечению, содержательному заполнению свободного времени, а удачное решение заданий разной степени сложности не только стимулирует познавательные процессы человека, но и способствует повышению его самооценки.

В целом целесообразно заметить, что функциональный потенциал людической коммуникации более дифференцирован, чем это представляется на первый взгляд, и весьма богат, причем сфера ее функционирования сегодня постоянно расширяется, проникая в ранее не свойственные ей сферы, например, в научную коммуникацию. И данное обстоятельство подтверждает вывод текстологов относительно гибридизации текста как одной из доминирующих в современной культуре тенденции.

\section{Кроссворд как источник сведений о знании, разделяемом всеми носителями языка и культуры}

Популярность и востребованность кроссворда в людической коммуникации трудно понять, если не принять во внимание, что его функционал зиждется, очевидно, на знании, разделяемом всеми носителями языка и культуры. В этом несложно убедиться, если проанализировать, как, какие сведения, сведения из каких тематических сфер активизируются в кроссвордах различными способами (табл. 1-3) [18].

Т а б ли ца 1

Основные тематические сферы в немециких кроссвордах

\begin{tabular}{|l|c|l|}
\hline \multicolumn{1}{|c|}{ Тематическая сфера } & Доля в \% & \multicolumn{1}{c|}{ Примеры } \\
\hline Культурная специфика & 15 & $\begin{array}{l}\text { franz. weiblicher Artikel (la), englisch eins (one), engl. Adelstitel Herzog } \\
\text { (duke) }\end{array}$ \\
\hline География и географические названия & 10 & Fluss in Russland (Newa), Sibirischer Strom (Ob) \\
\hline Животный и растительный мир & 9 & Karpfenfisch (Barbe), Zehnfußkrebs (Garnele) \\
\hline Религия & 5 & $\begin{array}{l}\text { griechischer Liebesgott (Eros), ägyptische Göttin (Isis), Korankapitel } \\
\text { (Sure) }\end{array}$ \\
\hline Литература & 4 & Roman von Herman Merville (Mobydick) \\
\hline Имена известных личностей & 4 & amerikanischer Schriftsteller (John) Irving \\
\hline Задания на синонимы & 25 & $\begin{array}{l}\text { unglaublich, unempört (unerhört), Käufer (Kunde), kreisen, wenden } \\
\text { (drehen) }\end{array}$ \\
\hline Всего & 72 & \\
\hline Иные тематические сферы & 28 & \\
\hline
\end{tabular}

Анализ показывает, насколько значимой в количественном и качественном отношении оказывается культурная специфика для адресанта, который не может не учитывать особенности организации сведений о мире в картине мира коллективного субъекта как носителя языка и культуры (ср. данные в табл. 1 и 2). И хотя очевидно, что полученный результат вряд ли позволяет из-за ограниченности изученных разновидностей кроссворда и не столь обширного эмпирического материала безапелляционно сформулировать значимое и сущностное обобщение, все-таки не стоит и преуменьшать ин- формативность полученных данных. Сравним только частотность активизации сведений из той или иной тематической сферы в отдельных языковых культурах (см. табл. 1 и 2) или же способы активизации сведений из одной тематической сферы в разных культурах. В русской культуре, например, сведения о животном и растительном мире (в частности, о рыбе определенного вида) могут активизироваться явно через приемы людической коммуникации (концептуальная метафора или персонификация): Karpfenfisch (Barbe) - pыба с односторонним взглядом на жизнь (камбала). 
Основные тематические сферы в русских кроссвордах

\begin{tabular}{|l|c|l|}
\hline \multicolumn{1}{|c|}{ Тематическая сфера } & Доля в \% & \multicolumn{1}{|c|}{ Примеры } \\
\hline Растительный и животный мир & 13 & рыба с односторонним взглядом на жизнь (камбала) \\
\hline Искусство и культура & 8 & музыкально-инструментальная пьеса (соната) \\
\hline Предметы быта & 8 & металлический декор сундука (оковка) \\
\hline География и географические термины & 6 & река на Ближнем Востоке (Иордан) \\
\hline Бизнес & 6 & гроза речных браконьеров (Роскомнадор) \\
\hline Литература и лингвистика & 6 & романтическая концовка (эпилог) \\
\hline Исторические события & 4 & дело рук монголо-татар (иго) \\
\hline Имена известных личностей & 5,5 & Бёртон или Роббинс (Тим) \\
\hline Военное дело & 4 & боевое столкновение войск (сражение) \\
\hline Всего & 56,5 & \\
\hline Иные тематические сферы & 43,5 & \\
\hline
\end{tabular}

Наряду с упомянутыми в табл. 2 тематическими сферами в русских кроссвордах разнообразными способами активизируются сведения также из других тематических сфер:

- транспорт: задняя часть судна, лодки и некотоpых других транспортных средств (корма);

- спорт: скачки трехлеток (дерби);

- религия: имя бога в исламе (Аллах);

- мифы и легенды: нимфа деревьев (дриада), злобное сказочное сущуество (орк);

- чувства и эмоции: учитель мудрых (горе), сильное возбуждение, задор (азарт);

- еда/пища: пирожное из взбитых яичных белков и сахара (безе);

- естественные науки: оптический прибор, применяемый для получения увеличенного изображения на экране (проектор).

Тот факт, что в разных языковых культурах при конструировании кроссворда задействуются одина- ковые способы активизации сведений из сопоставимых тематических сфер (табл. 3), свидетельствует, с одной стороны, о правомерности вычленения интегральных текстовых признаков как для текста вообще, так и для текста определенного типа в частности. С другой стороны, сопоставление способов активизации сведений о мире в разных культурах наглядно демонстрирует разную функциональную нагрузку того или иного способа апелляции к знанию, разделяемому всеми носителями языка и культуры при решении ими одинаковых коммуникативных и когнитивных задач.

Тем самым очевидно, что с помощью текстограмматических приемов описания разнообразных коммуникативных образований можно получить лингвистически верифицируемые данные, обладающие довольно высокой объяснительной силой как в общетеоретическом, так и в частнотеоретическом смысле.

Способы активизаџии сведений в кроссвордах

\begin{tabular}{|l|c|c|}
\hline \multicolumn{1}{|c|}{ Способы активизации сведений } & $\begin{array}{c}\text { Русские кроссворды } \\
\text { (доля в \%) }\end{array}$ & $\begin{array}{c}\text { Немецкие кроссворды } \\
\text { (доля в \%) }\end{array}$ \\
\hline Дефиниция & 40 & 13 \\
\hline Синонимия & 3 & 23 \\
\hline Перифраз & 34 & 20 \\
\hline Запрос информации & 10 & 8 \\
\hline Класс объектов & 10 & 5 \\
\hline Аббревиатура & - & 5 \\
\hline Перевод лексем & - & 97 \\
\hline Всего & 97 & 3 \\
\hline Иные способы & 3 & \\
\hline
\end{tabular}




\section{Выводы}

Таким образом, обобщая наблюдения, следует сформулировать ряд тезисов, осмысляя которые, можно положительно ответить на поставленный в заголовке статьи вопрос.

Кроссворд - это тип текста, обладающий функциональной, содержательной, формальной целостностью и вместе с тем членимостью в содержательном, структурном, функциональном отношении.

Кроссворд - креолизованный, семиотически осложненный (полимодальный/поликодовый) текст с полной степенью креолизации. Функциональный потенциал вербальных и невербальных средств при реализации когерентности и выражении текстовых категорий более или менее равноправен.

Будучи текстом, кроссворд обладает всеми признаками, присущими тексту как феномену. Являясь текстом определенного типа, кроссворд обнаруживает интегральные и дифференциальные признаки, свойственные ему как типу текста, а также вариативность в структурном, содержательном и функциональном отношении.

Когерентность в кроссворде реализуется с помощью вербальных и невербальных средств. Одним из доминирующих способов установления когерентности является апелляция с помощью разнородных средств к знанию, разделяемому всеми носителями языка и культуры.

Кроссворд - продукт людической деятельности человека. Его функциональные, структурные, содержательные особенности, а также особенности организации на микро- и макротекстовом уровне обусловлены данным обстоятельством.

\section{ЛИТЕРАТУРА}

1. Гришаева Л. И. Варьирование текста в коммуникации. Воронеж : НАУКА-ЮНИПРЕСС, 2020. 291 с.

2. Grischaewa L. I. Homo ludens, Fake News und Text, oder warum ändern sich die Textgestaltungsprinzipien? // Русская германистика : Ежегодник Рос. союза германистов. Т. 17: Типология текстов и дискурсивные практики в немецкоязычном культурном пространстве. М. : ФЛИНТА, 2020. С. 24-47.

3. Волкова М. В. Загадка и кроссворд как типы текста : семантический и прагматический аспекты : на материале немецкого языка : дис. ... канд. филол. наук. Смоленск, 2011. 167 с.

4. Isenberg $H$. Texttypen als Interaktionstypen. Eine Texttypologie // Zeitschrift für Germanistik. Leipzig, 1984. Heft 3. S. 261-270.

5. Adamzik K. Textsorten - Texttypologie. Eine kommentierte Bibliographie. B. 12. Münster : Nodus Verlag, 1995. $301 \mathrm{~S}$.

6. Бабенко Н. C. Textsortenlinguistik vs лингвистическое жанроведение // Русская германистика : ежегод- ник Рос. союза германистов. Т. 5. М. : Языки славянской культуры, 2009. С. 235-244.

7. Бокова О. В. Особенности семантической и синтаксической организации немецкоязычных медийных сообщений о преступлениях. Воронеж : Воронеж. гос. пед. ун-т, 2013. 244 с.

8. Никонова М. Н. Теория текста. Омск : Изд-во ОмГТУ, 2008. $241 \mathrm{c.}$

9. Макаренко О. С. Средства и способы активизации сведений о мире в немецком и русском кроссворде // Русская германистика : ежегодник Рос. союза германистов. Т. 17: Типология текстов и дискурсивные практики в немецкоязычном культурном пространстве. М. : ФЛИНТА, 2020. С. 335-356.

10. Driesen B. Das Kreuzworträtsel wird 100. Weser Kurier, 2013. URL: https://www.weser-kurier.de/spiel-undspass_artikel,-Das-Kreuzwortraetsel-wird-100-_arid, 739158.html

11. Набоков В. Память, говори. Нью-Йорк : Голланц, Юниверсал Лайбрэри, 1951. URL: http://nabokov-lit.ru/ nabokov/proza/pamyat-govori/pamyat-govori-14.htm

12. Tsvasman $L$. Informationsgesellschaft [information society] // Tsvasman L. R. (Hrsg.) Das große Lexikon. Medien und Kommunikation. Würzburg : Ergon-Verlag, 2006. S. 134-141.

13. Tsvasman L. Manipulation [manipulation] // Tsvasman L. R. (Hrsg.) Das große Lexikon. Medien und Kommunikation. Würzburg : Ergon-Verlag, 2006. S. 226-228.

14. Анисимова E. E. Религиозный дискурс : функциональный и антропологический аспекты. М. : МГЛУ, 2019. $240 \mathrm{c}$.

15. Fix U. Texte und Textsorten - sprachliche, kommunikative und kulturelle Phänomene. Berlin : Frank \& Timme, 2008. $506 \mathrm{~S}$.

16. Freudenberg-Findeisen R. (Hg.) Auf dem Weg zu einer Textsortendidaktik. Linguistische Analyse und text(sorten)didaktische Bausteine nicht nur für den fremdsprachlichen Deutschunterricht. Georg Olms Verlag Hildesheim ; Zürich ; New York, 2016. 308 S.

17. Text-Brücken zwischen den Kulturen. Festschrift zum 70. Geburtstag von Bernd Spillner. Hrsg. von Nadine Rentel und Elisabeth Venohr. Frankfurt/M. ; Berlin ; Bern ; Bruxelles ; New York ; Oxford ; Wien Peter Lang, 2012. $513 \mathrm{~S}$.

18. Макаренко О. С. Средства активизации сведений о мире в русских и немецких кроссвордах : дипломная работа (научный руководитель - Л. И. Гришаева). Воронеж, 2021. 86 c.

19. Grischaewa L. I. Makro-Textsortenanalyse : Universelles und Kulturspezifisches // Renate FreudenbergFindeisen (Hg.). Auf dem Weg zu einer Textsortendidaktik. Linguistische Analyse und text(sorten)didaktische Bausteine nicht nur für den fremdsprachlichen Deutschunterricht. Hildesheim ; Zürich ; New York : Georg Olms Verlag, 2016. S. $69-81$.

20. Dressler $W$. Einführung in die Textlinguisitk. Tübingen : Max Niemeyer, 1973. 134 S. 
21. Helbig $G$. Entwicklung der Sprachwissenschaft seit 1970. Leipzig : Bibliographisches Institut, 1975. $323 \mathrm{~S}$.

22. Beaugrande de R.-A., Dressler W. U. Einführung in die Textlinguistik. Tübingen : Niemeyer, 1981.290 S.

23. Гальперин И. Р. Текст как объект лингвистического исследования. М. : Прогресс, 1981. 144 с.

24. Москальская О. И. Грамматика текста. М. : Высшая школа, 1981. $183 \mathrm{c}$.

25. Moskalskaja O. Textgrammatik. Leipzig : Bibliographisches Institut, 1984. $171 \mathrm{~S}$.

26. Шендельс Е. И. Некоторые проблемы грамматики текста // Современные зарубежные грамматические теории : сб. науч.-аналит. обзоров. М. : ИНИОН, 1985. С. 30-67.

27. Brinker $\mathrm{Kl}$. Linguistische Textanalyse. Eine Einführung in Grundbegriffe und Methoden. Berlin : Erich Schmidt Verlag, 1997. 165 S.

28. Heinemann M., Heinemann W. Grundlagen der Textlinguistik. Interaktion - Text - Diskurs. Tübingen : Max Niemeyer Verlag, 2002. $281 \mathrm{~S}$.

29. Fix U. Was ist kulturspezifisch an Texten? Argumente für eine kulturwissenschaftlich orientierte Textsortenforschung // Русская германистика : ежегодник Рос. союза германистов. Т. 8. М. : Языки славянской культуры, 2011. С. 172-183.

30. Spillner B. Kontrastive Textologie : Sprachliche und kulturelle Grenzüberschreitungen // Русская германистика : ежегодник Рос. союза германистов. Т. 8. М. : Языки славянской культуры, 2011. С. 212-220.

31. Языкознание. Большой энциклопедический словарь / гл. ред. В. Н. Ярцева. М. : Большая российская энциклопедия, 2000. $688 \mathrm{c.}$

32. Schmitz U. Kohärenz in Text-Bild-Sorten : Grammatik \& Design // Субъект познания и коммуникации : языковые и межкультурные аспекты. Воронеж : НАУКА-ЮНИПРЕСС, 2014. С. 226-244.

33. Анисимова E. E. Лингвистика текстов и межкультурная коммуникация (на материале креолизованных текстов). М. : Тезаурус, 2013. 122 с.

34. Хёйзинга Й. Homo Ludens : статьи по истории культуры / пер. с гол. Д. В. Сильвестрова. М. : Прогресс ; Традиция, 1997. 416 с.

35. Назарова Р. 3., Золотарев М. В. Прецедентные феномены : проблемы дефиниции и классификации // Известия Сарат. ун-та. Новая серия. Сер.: Филология. Журналистика. Саратов, 2015. С. 29-32.

\section{ИСТОЧНИКИ}

1. Kreuzwort. Rätsel, die Spaß machen! // Deutscher Rätselverlag. 2016. Band 16. $66 \mathrm{~S}$.

2. Хит-Сканворд // ред. Мир новостей. М., 2009. № 6 (66). 98 c.

3. Сайт онлайн-кроссвордов, сканвордов, кейвордов, японских кроссвордов и прочих головоломок. URL: http://crossword-best.ru/

4. Список новых кроссвордов. URL: https://kotvet. $\mathrm{ru} / \mathrm{spisok} /$

\section{REFERENCES}

1. Grishaeva K. I. Var'irovanike teksta v kommunikacii [Variation of text in communication]. Voronezh: NAUKA-YUNIPRESS, 2020. 291 p.

2. Grischaewa L. I. Homo ludens, Fake News und Text, oder warum ändern sich die Textgestaltungsprinzipien? [Homo ludens, Fake News and Text, or why do the text design principles change?]. In: Russkaja germanistika: Jezhegodnik Rossijskogo sojuza germanistov. T. 17: Tipologija tekstov I doskursivnyje proktiki v nemeckojazyčnom kulturnom prostranstve. Moskva: FLINTA, 2020. Pp. 24-47.

3. Volkova M. V. Sagadka I krossvord kak tipy teksta: semantičeskij I pragmatičceskij aspekty: na material nemeckogo jazyka [Riddle and Crossword as Text Types: Semantic and Pragmatic Aspects: In German]: dis. ... kand. filol. nauk. Smolensk, 2011. 167 p.

4. Isenberg H. Texttypen als Interaktionstypen. Eine Texttypologie [Text types as interaction types. A text typology]. In: Zeitschrift für Germanistik. Leipzig, 1984. Heft 3. S. 261-270.

5. Adamzik K. Textsorten - Texttypologie. Eine kommentierte Bibliographie. [Text Types - Text Typology. An annotated bibliography]. B. 12. Münster: Nodus Verlag, 1995. $301 \mathrm{~S}$.

6. Babenko N. S. Textsortenlinguistik vs lingvističeskoje zhanrovedenie [Text Type Linguistics vs. linguistic genre study]. In: Russkaja germanistika: Jezhegodnik Rossijskogo sojuza germanistov. T. 5. Moskva: Jazyki slavjanskoi kultury, 2009. Pp. 235-244.

7. Bokova O. V. Osobennosti semantičeskoi I sintaksičeskoi organisacii nemeckojazyčnych medinych soobščenij o prestuplenijach [Peculiarities of the Semantic and Syntactic Organization of German-Language Media Crime Reports]. Voronezh: Voronezhskij gosudarstvennyi pedagogičeskij universitet, 2013. $244 \mathrm{p}$.

8. Nikonova M. N. Teorija teksta [Text Theory]. Omsk: Isdatelstvo OmGTU, 2008. $241 \mathrm{p}$.

9. Makarenko O. S. Sredstva I sposoby aktivisacii cvedenij o mire v nemeckom I russko krossvorde [Means and methods of activation of information about the world in the German and Russian crossword puzzle]. In: Russkaja germanistika: Jezhegodnik Rossijskogo sojuza germanistov. T. 17: Tipologija tekstov I doskursivnyje proktiki v nemeckojazyčnom kulturnom prostranstve. Moskva: FLINTA, 2020. Pp. 335-356.

10. Driesen B. Das Kreuzworträtsel wird 100 [The crossword puzzle turns 100]. Weser Kurier, 2013. Available at: https://www.weser-kurier.de/spiel-und-spass_artike1,-Das-Kreuzwortraetsel-wird-100-_arid,739158.html

11. Nabokov V. Pamjat', govori [Speak, Memory]. N'u Jork: Gollanc, Juniversal Laibreri, 1951. Available at: http:// nabokov-lit.ru/nabokov/proza/pamyat-govori/pamyat-govori-14.htm

12. Tsvasman L. Informationsgesellschaft [information society]. In: Tsvasman L. R. (Hrsg.) Das große Lexikon. Medien und Kommunikation. Würzburg: Ergon-Verlag, 2006. S. 134-141. 
13. Tsvasman L. Manipulation [manipulation]. In: Tsvasman L. R. (Hrsg.) Das große Lexikon. Medien und Kommunikation. Würzburg: Ergon-Verlag, 2006. S. 226-228.

14. Anisimova E. E. Religiosnyi diskurs: funkcionalnyi I antropologičeskij aspekty [Religious Discourse: Functional and Anthropological Aspects]. Moskva: FGBOU VO MGLU, 2019. 240 p.

15. Fix U. Texte und Textsorten - sprachliche, kommunikative und kulturelle Phänomene [Texts and text types linguistic, communicative and cultural phenomena]. Berlin: Frank \& Timme, 2008. $506 \mathrm{~S}$.

16. Freudenberg-Findeisen R. (Hg.) Auf dem Weg zu einer Textsortendidaktik. Linguistische Analyse und text (sorten)didaktische Bausteine nicht nur für den fremdsprachlichen Deutschunterricht [On the way to a didactics of text types. Linguistic analysis and text (type) didactic building blocks not only for teaching German as a foreign language]. Georg Olms Verlag Hildesheim - Zürich - New York, 2016. $308 \mathrm{~S}$.

17. Text-Brücken zwischen den Kulturen. Festschrift zum 70. Geburtstag von Bernd Spillner. Hrsg. von Nadine Rentel und Elisabeth Venohr [Text-Bridges between Cultures. Festschrift on the occasion of the 70th birthday of Bernd Spillner. Edited by Nadine Rentel and Elisabeth Venohr]. Frankfurt/M., Berlin, Bern, Bruxelles, New York, Oxford, Wien: Peter Lang, 2012. 513 S.

18. Makarenko O. S. Sredstva arktivisacii cvedenij o mire $\mathrm{v}$ russkich I nemeckich krossvordach [Means of activating of information about the world in Russian and German crossword puzzles]. Diplomnaja rabota (Naučnuj rukovoditel - L. I. Grišaeva). Voronezh, 2021. 86 p.

19. Grischaewa L. I. Makro-Textsortenanalyse: Universelles und Kulturspezifisches. In: Renate Freudenberg-Findeisen (Hg.). Auf dem Weg zu einer Textsortendidaktik. Linguistische Analyse und text(sorten)didaktische Bausteine nicht nur für den fremdsprachlichen Deutschunterricht [Macro text type analysis: universal and culture-specific. In: Renate Freudenberg-Findeisen (Ed.). Towards a didactics of text types. Linguistic analysis and text (types) didactic building blocks not only for teaching German as a foreign language]. Hildesheim - Zürich - New York : Georg Olms Verlag, 2016. S. 69-81.

20. Dressler W. Einführung in die Textlinguisitk [Introduction to text linguistics]. Tübingen: Max Niemeyer, 1973. $134 \mathrm{~S}$.

21. Helbig G. Entwicklung der Sprachwissenschaft seit 1970 [Development of linguistics since 1970]. Leipzig: Bibliographisches Institut, 1975. $323 \mathrm{~S}$.

22. Beaugrande de R.-A., Dressler W. U. Einführung in die Textlinguistik [Introduction to text linguistics]. Tübingen: Niemeyer, 1981. $290 \mathrm{~S}$.

23. Galperin I. R. Tekst kak ob'ekt lingvističeskogo issledovanija [Text as an object of linguistic research]. Moskva: Progress, 1981. 144 p.

24. Moskalskaja O. I. Grammatika teksta [Text Grammar]. Moskva : Vysšaja škola, 1981. 183 p.

25 Moskalskaja O. Textgrammatik [Text Grammar]. Leipzig: Bibliographisches Institut, 1984. $171 \mathrm{~S}$.
26. Šendels E. I. Nekotoryje problem grammatiki teksta [Some Problems of Text Grammar]. In: Sovremennyje sarubezhnyje grammatičeskije teorii. Sbornik naučno-analitičeskich obsorov. Moskva: INION, 1985. Pp. 30-67.

27. Brinker Kl. Linguistische Textanalyse. Eine Einführung in Grundbegriffe und Methoden [Linguistic Text Analysis. An introduction to basic concepts and methods]. Berlin: Erich Schmidt Verlag, 1997. 165 S.

28. Heinemann M., Heinemann W. Grundlagen der Textlinguistik. Interaktion - Text - Diskurs [Fundamentals of text linguistics. Interaction - Text-Discourse]. Tübingen: Max Niemeyer Verlag, 2002. $281 \mathrm{~S}$.

29. Fix U. Was ist kulturspezifisch an Texten? Argumente für eine kulturwissenschaftlich orientierte Textsortenforschung [What is culturally specific about texts? Arguments for a culturally oriented text type research]. In: Russkaja germanistika: Jezhegodnik Rossijskogo sojuza germanistov. T. 8. Moskva: Jazyki slavjanskoi kultury, 2011. Pp. 172-183.

30. Spillner B. Kontrastive Textologie: Sprachliche und kulturelle Grenzüberschreitungen [Contrastive Textology: Linguistic and Cultural Border Crossings]. In: Russkaja germanistika: Jezhegodnik Rossijskogo sojuza germanistov. T. 8. Moskva: Jazyki slavjanskoi kultury, 2011. Pp. 212-220.

31. Jasykosnanije. Bolšoj enciklopedičeskij slovar [Linguistics. The Great Encyclopedic Dictionary] / Gl. redaktor V. N. Jarceva. Moskva: Bolšaja Rossijskaja enciklopedija, 2000. $688 \mathrm{p}$.

32. Schmitz U. Kohärenz in Text-Bild-Sorten: Grammatik \& Design [Coherence in text-image varieties: grammar \& design]. In: Sub'ekt posnanija I kommunikacii: jasykovyje i mezhkultuurnyje aspekty. Voronezh: NAUKA-JUNIPRESS, 2014. Pp. 226-244.

33. Anisimova E. E. Lingvistika i mezhkulturnaja kommunikacija (na material kreolisovannych tekstov) [Text Linguistics and Intercultural Communication (on the Material of Creolized Texts)]. Moskva: Tesaurus, 2013. 122 p.

34. Huizinga J. Homo Ludens; Stat'i po istorii kultury [Articles on cultural history]. Per. s gol. D. V. Silverstrova. Moskva: Progress ; Tradicija, 1997. 416 p.

35. Nasarova R. S., Solotarjov M. V. Precedentnyje fenomeny: problem definicii I klassifikacii [Precedent Phenomena: Problems of Definition and Classification]. In: Isvestija Saratovskogo universiteta. Novaja serija. Serija: Filologija. Zhurnalistika. Saratov, 2015. Pp. 29-32.

\section{SOURCES}

1. Kreuzwort. Rätsel, die Spaß machen! [Crossword. Puzzles that are fun]. In: Deutscher Rätselverlag. 2016. Band 16.66 S.

2. Chit-skanvord [Hit-scanword]. In: red. Mir novostej. Moskva, 2009. No. 6 (66). 98 p.

3. Sait on-line-krossvordov, skanvordov, keivordov, japonskich krossvordov I pročich golovolomok [Online crossword puzzles, scandals, puzzles, Japanese crossword puzzles and other puzzles]. Available at: http://crossword-best.ru/

4. Spisok novych krossvordov [List of new crossword puzzles]. Available at: https://kotvet.ru/spisok/ 
Воронежский государственный университет Гришаева Л. И., профессор кафедры немеикой филологии

E-mail: grischaewa@rgph.vsu.ru

Макаренко O. C., студент

E-mail: makarenko.olesia@yandex.ru

Поступила в редакциию 9 июля 2021 г.

Принята к публикаџчи 15 октября 20212.

\section{Для цитирования:}

Гришаева Л. И., Макаренко О. С. Почему кроссворд является текстом? // Вестник Воронежского государственного университета. Серия: Лингвистика и межкультурная коммуникация. 2021. № 4. C. 6-19. DOI: https://doi.org/10.17308/lic.2021.4/3805
Voronezh State University

Grishaeva L. I., Professor of the German Philology Department

E-mail: grischaewa@rgph.vsu.ru

Makarenko O. S., Student

E-mail: makarenko.olesia@yandex.ru

Received: 9 July 2021

Accepted: 15 October 2021

\section{For citation:}

Grishaeva L. I., Makarenko O. S. Why is a crossword puzzle a text? Proceedings of Voronezh State University. Series: Linguistics and Intercultural Communication. 2021. No. 4. Pp. 6-19. DOI: https://doi.org/10.17308/lic.2021.4/ 3805 